\author{
Mahmood M. Barbooti \\ Department of Applied \\ Science, University of \\ Technology, P.O. Box 35045, \\ Baghdad, Iraq.
}

\section{Shaymaa S. Hasan, \\ Department of Applied \\ Science, University of \\ Technology, Baghdad, Iraq.}

\author{
Mustafa Jassim \\ Department of Applied \\ Science, University of \\ Technology, Baghdad,Iraq.
}

Received on: 21/09/2018

Accepted on: 17/03/2019

Published online: 25/04/2019

\title{
Evaluation of Water Treatment Residue as a Sorption Medium and its Application to Control Phosphate Level in Water
}

\begin{abstract}
Wastewater treatment residual material, WTR, from a local drinking water facility in Baghdad, was evaluated as a potential medium for the removal of some unwanted species from water. The material was first characterized by chemical composition, X-ray diffraction and infrared spectral analysis prior to its use as an adsorbent. The $x$-ray revealed that the material is a calcium based water treatment residue mixed with silica and impurities of oxides like $\mathrm{MgO}$ and $\mathrm{Fe}_{2} \mathrm{O}_{3}$. The adsorption characteristics of the material were evaluated by studying the adsorption of methylene blue. The cation exchange capacity and the surface area had values of $10.5 \mathrm{mmol}$ per100 $\mathrm{g}$ and $87.5 \mathrm{~m}^{2} \cdot \mathrm{g}^{-1}$, respectively. The sorption capacity of the material was applied to control the phosphate concentration in water. Time and adsorbent amount have played significant roles in the removal of phosphate from water. An adsorption capacity had a value of $1.6 \mathrm{mg} \mathrm{PO}_{4}^{3-} \cdot \mathrm{g}^{-1}$ of WTR.
\end{abstract}

Keywords- Kaolin-polyacrylamide composite, Nickel adsorption, experimental design; optimization, adsorption (efficiency and capacity)

How to cite this article: M.M. Barbooti, Sh.S. Hasan and M. Jassim, "Evaluation of Water Treatment Residue as a Sorption Medium and its Application to Control Phosphate Level in Water," Engineering and Technology Journal, Vol. 37, Part C, No. 1, pp. 126-131, 2019.

\section{Introduction}

There exists a growing interest in the search for low cost and reliable adsorbents for the removal of pollutants from water. Various materials were suggested and used on lab and pilot scales as potential sorbents such as residual chars from plant materials, clay minerals, fly ashes, etc. De Gisi et al. [1] have reviewed the characteristics and adsorption capacities of so many sorbents for wastewater treatment to remove organic and inorganic pollutants. The introduction of a new adsorbent for use in environmental applications must be aided by procedures for the evaluation of sorption characteristics using methylene blue, $\mathrm{MB}$, dye from aqueous solutions [2]. The MB method yields accurate prediction of some sorbent index properties and can be easily applied with simple test equipment [2].

Lee et al. have studied the use of aluminum-based WTR for the phosphate adsorption to examine the effect of $\mathrm{pH}$, range of particle size in addition to temperature [3]. The increase of WTR particle sizes caused a decrease in adsorption rate. The use of fine WTR particles at $\mathrm{pH} 4$ resulted in the highest $\mathrm{P}$ adsorption capacity, $15.57 \mathrm{mg} \mathrm{PO}_{4}^{-} / \mathrm{g}$ WTR. Higher $\mathrm{pH}$ ranges (7-9) has required much longer sorption time. Zhou and Haynes, 2010, reviewed the effect of working parameters on the sorption efficiency of heavy metal ions on WTR [4]. Sarkar et al. [5] evaluated the sorption of two As species by Fe- and Al-based WTR as affected by the particle size at different $\mathrm{pH}$ values. Both WTRs showed high affinity for As oxyanions. Suda et al. [6] used WTR to stabilize arsenic in flooded soils and attenuate arsenic uptake by rice (Oryza sativaL.) plants. Drinking Water Treatment Residual was characterized by Zhao et al. [7] as a novel pesticides adsorbent. The WTRs exhibited a greater affinity for chlorpyrifos accompanied by a high sorption capacity $(\mathrm{KF}=$ 5967 mg1-n.L.Kg-1 due to the type and content of organic matter. Park et al. [8] studied the utilization of WTR as substitute soil to enhance plant growth. A cost-effective remediation method could be established by the in situ application of Ca-WTR for soils the contaminated with $\mathrm{Cu}$ without affecting citrus production [9]. The use of dewatering WTR will alter its ability to decrease the $\mathrm{P}$ soil concentrations. It also affects the metal concentrations [10].

Eutrophication processes pose a serious threat for the surface water bodies. Phosphate represents a major cause of eutrophication and excess of biogenic substances coming from drainage areas deteriorates the quality values of natural waters, and results in changes in the structure of water body ecosystems. They triggers vigorous growth of cyanobacteria, reduces dissolved oxygen content, and consequently suffocates fish populations. The process will complicate water purification. There must be means for the minimization of biogenic discharge of nitrogen 
and phosphorus compounds into the water bodies. The removal of phosphate from the wastewater is another mean for the control of these species from water. Ruzhitskaya and Gogina [11] have summarized the methods of phosphate removal from wastewater. Chang-jun, et al. used active red mud and a waste of alumina industry, for the adsorption of phosphate from water. The adsorption process followed well the Langmuir isotherm model with maximum adsorption capacities of the acid-heat activated red mud and the heat activated samples of $202.9 \mathrm{mg} \mathrm{P} / \mathrm{g}$ and $155.2 \mathrm{mg} \mathrm{P} / \mathrm{g}$, respectively [12]. Barbooti, has used magnesium oxide for the control of phosphate in water originating from the application of cattle manure for soil amendment [13]. Recently, Goscianska, et al., succeeded to remove phosphate from water by lanthanummodified zeolites derived from fly ash. The sorption capacities of the particular samples were in the range of 44.0 - $58.2 \mathrm{mg} . \mathrm{g}-1$ [14]. Recently, Wang et al., examined the activity of WTR as an additional medium in columns for effective $\mathrm{P}$ removal from eutrophic surface water .

The present work is an attempt to evaluate the potentials of WTR from a local drinking water facility as a sorbent by methylene blue adsorption and its application for phosphate removal from aqueous solutions.

\section{Materials and methods}

\section{Apparatus}

The concentration of phosphate and methylene blue was measured by spectral absorption on a EMC Lab, GMBH, Germany, (UV-1100) spectrophotometer. The infrared spectra were recorded on a Fourier Transform infrared, FTIR, spectrometer from Shimadzu (8300) on $\mathrm{KBr}$ discs. The X-ray diffraction, XRD, measurements were recorded on a diffractometer from FEI Co., F350 NE Dawson Creek Drive Hillsboro, 9712, USA. The sorption experiments involved the shaking of the samples with Genex, shaker, Florida, USA.

\section{Materials and reagents}

The phosphate standard solution was prepared from potassium dihydrogen phosphate supplied from $\mathrm{BDH}$. The $\mathrm{MB}$ and ammonium $p$-molybdate were supplied from Reidel de Haene, Germany; The WTR was obtained from a local drinking water facility in Baghdad. It was naturally dried and ground in an agate mortar to pass $0.06 \mathrm{~mm}$ mesh.

\section{Procedures}

The CEC determination: A known amount $(2.00 \mathrm{~g})$ of the material was mixed with distilled water $(300 \mathrm{~mL})$ in a beaker. Sufficient sulfuric acid was also added with stirring to acidify the solution to a $\mathrm{pH}$ range of 2.5 to 3.8 . The methylene blue solution $(0.01 \mathrm{M})$ was placed in a burette. Aliquot of $5 \mathrm{~mL}$ of the solution was added to the slurry and the mixture was stirred for 1 to $2 \mathrm{~min}$. A drop of the water-WTR suspension was placed near the circumstance of a filter paper. One $\mathrm{mL}$ increments of the methylene blue solution were added to the slurry with 1 to $2 \mathrm{~min}$ of stirring after each addition, followed by transferring a drop onto on the filter paper [16]. To indicate the end point a light blue halo around the drop forms [17].

Surface area determination: The specific surface area can also be determined from the MB adsorption results by Santarina et al., [18]. From the area covered by one methylene blue molecule is typically was assumed to be $130 \AA 2(1 \AA=0.1$ $\mathrm{nm})$ the overall surface area of the sorbent was measured. It is important to highlight that the technique is done in water suspensions. Thus expansive minerals can expose all available surface area [19]. The value of the specific surface was derived from the point of complete cation replacement determined on the titration curve. The step-by-step procedure was given as follows:

- Accurately about $2.0 \mathrm{~g}$ of the dry specimen was mixed with $200 \mathrm{~mL}$ of deionized water;

- The MB solution was added to the soil suspension and

continually mixed for about $2 \mathrm{~h}$,

The mixture was then left overnight to reach absorption equilibrium and allow particle settlement;

- Five mLs aliquot of the fluid was carefully removed and placed in a test tube and centrifuged;

- The remnant concentration of MB in the fluid was measured (spectrophotometer, wavelength $=$ $666 \mathrm{~nm}$, was used);

More MB solution was added and the previous steps were repeated (for convenience, a set of suspensions can be prepared in advance);

Adsorption study: In $60-\mathrm{mL}$ capacity plastic containers, weighed amounts of the WTR $(0.05$, $0.10,0.15$ and $0.220 \mathrm{~g}$ ) were placed and fixed amount of MB solution $(2 \mathrm{~mL})$ was added. The volume was completed up to $50 \mathrm{~mL}$ with deionized water. The container was capped and further wrapped with Parafilm. The containers were placed on the top of the rotary shaker and 
shaken at $250 \mathrm{rpm}$. The containers were removed from the shaker at various time intervals $(22,35$ and $60 \mathrm{~min}$.), centrifuged and filtered with syringe filters with a pore size of $0.2 \mu$. The filtrates were analyzed by spectral absorption.

Phosphate removal experiments: In a set of seven containers, aliquots of phosphate solution that makes $50 \mathrm{mg} . \mathrm{L}-1$ when diluted to the final volume $(50 \mathrm{~mL})$ were placed, a fixed amount of WTR $(0.4 \mathrm{~g})$ was added. No adjustment of $\mathrm{pH}$ was made, nor any $\mathrm{KCl}$ was added to mimic normal wastewater environment. The containers were placed on the top of the rotary shaker operating at $250 \mathrm{rpm}$ to be removed after a predetermined time of equilibration. The samples were filtered with a microsyringe $(0.2 \mu)$ and the filtrate was kept at $4^{\circ} \mathrm{C}$ until the analysis time. The sample solutions together with standard phosphate solutions were analyzed on the same day to insure similarity in analytical conditions.

To study the sorption activity of WTR towards $\mathrm{MB}$, a method was first established for the rapid analysis of samples after the sorption. The MB concentration was determined by the spectrophotometric method by measuring the absorbance of the solutions at $666 \mathrm{~nm}$.

\section{Results and Discussion}

\section{The WTR characterization}

The material was characterized by chemical analysis and found to be composed mainly of lime (or limestone), in addition to organic matter and other minor oxides (Table 1). Some of the calcium exists as other species like calcium silicate. To confirm the composition, the material was ignited at $800{ }^{\circ} \mathrm{C}$ to remove the organic material and decarboxylate limestone that may be present. Figure 1 shows the x-ray diffraction patterns of the WTR and its residue after burning at $800^{\circ} \mathrm{C}$. On ignition; the Calcium content was almost doubled accompanied by reduction of the carbon content by about $40 \%$. The low aluminum and iron content reflects the relatively small amounts of the alums and hence, low suspended matter in the treated water [21]. Such a composition is indicative of the differences in the composition of the local WTR in comparison with those employed in the published papers.

\begin{tabular}{lll}
\hline \hline \multirow{2}{*}{$\begin{array}{l}\text { Element, } \\
\%\end{array}$} & Sample & \\
\cline { 2 - 3 } & Dried WTR & Fired WTR \\
\hline $\mathrm{Ca}$ & 16.65 & 37.37 \\
$\mathrm{C}$ & 9.46 & 5.13 \\
$\mathrm{Si}$ & 8.51 & 5.68 \\
$\mathrm{Mg}$ & 4.15 & 1.57 \\
$\mathrm{Fe}$ & 2.81 & 2.38 \\
$\mathrm{Al}$ & 2.63 & 2.81 \\
$\mathrm{O}$ & 54.49 & 44.81 \\
\hline
\end{tabular}

Figure 2 shows the FTIR spectra of the dried WTR together with that burned at $850^{\circ} \mathrm{C}$. The spectrum of the dried material showed the main features being, 1420,874 and $710 \mathrm{~cm}^{-1}$ of the IR bands of calcium carbonate [21,22]. Also, the C$\mathrm{H}$ signals appeared in the $2900-3300 \mathrm{~cm}^{-1}$ ) referring to some organic contaminants. The wide and strong band within the $500 \mathrm{~cm}^{-1}$ regions can be attributed to the $\mathrm{Ca}-\mathrm{O}$ bond [23]. The main features of the spectrum vanished after burning of the WTR at $850^{\circ} \mathrm{C}$ indicating the degradation of the organic compounds and thermal decomposition of calcium carbonate. Only the features of the inorganic oxide residues persisted below the $1000 \mathrm{~cm}^{-1}$.

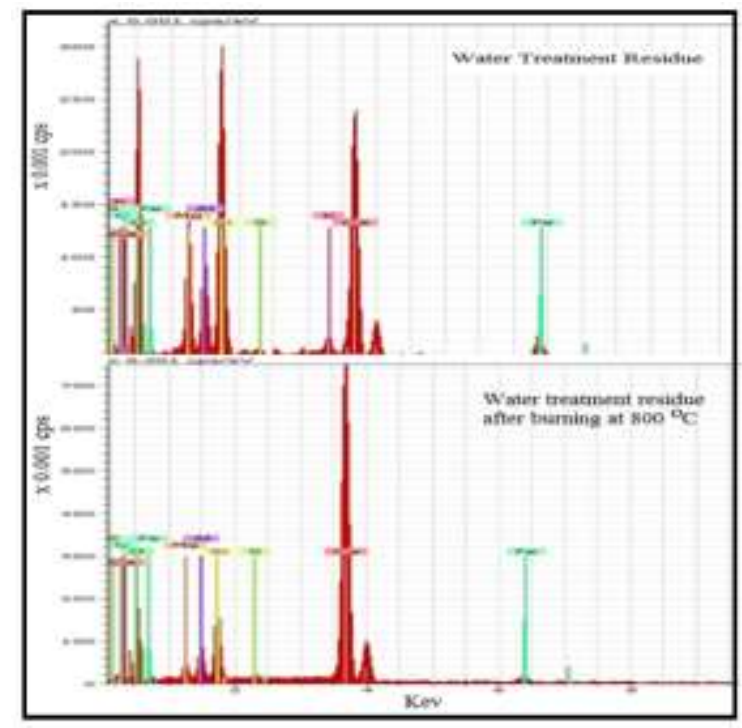

Figure 1: The $x$-ray diffraction patterns of the water treatment residue (upper) and after burning at $800^{\circ} \mathrm{C}$ (Lower). 


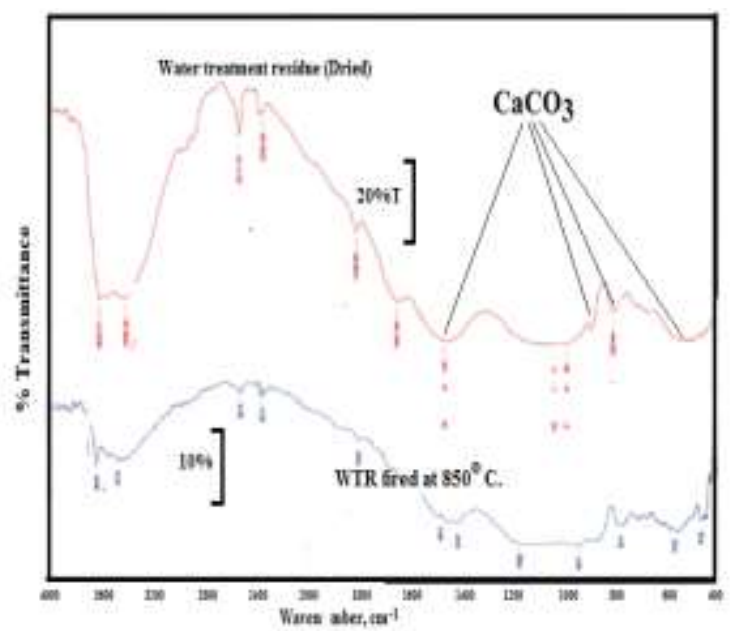

Figure 2 FTIR spectra of the dried WTR and that burned at $850^{\circ} \mathrm{C}$.

\section{Sorption activity}

The method is sensitive and indicated a linear calibration graph (Figure 3) with $\mathrm{R}^{2}$ of 0.997 and absorbance concentration relation as given in Equation 1:

Abs $=60.59 \mathrm{C}(\mathrm{M})+0.0596$

The determination of CEC was carried out based on the Standard Test Method for MB Index of Clay, (ASTM C 837 -81) [25]. The test was based on the linear relationship between the MB index and fundamental properties of the sorbent such as cation exchange capacity (CEC) and specific surface. The CEC could then be calculated as in equation (2):

$$
\mathrm{CEC}=(\mathrm{EV} / \mathrm{W}) * 100
$$

The CEC refers to the cation exchange capacity in meq/ $100 \mathrm{~g}$ of the WTR sample. The E was the number of $\mathrm{MB}$ milliequivalents per $/ \mathrm{mL}$. $\mathrm{V}$ is the volume of $\mathrm{MB}$ solution required for the titration, and $\mathrm{W}$ was the weight in grams of the dry material.

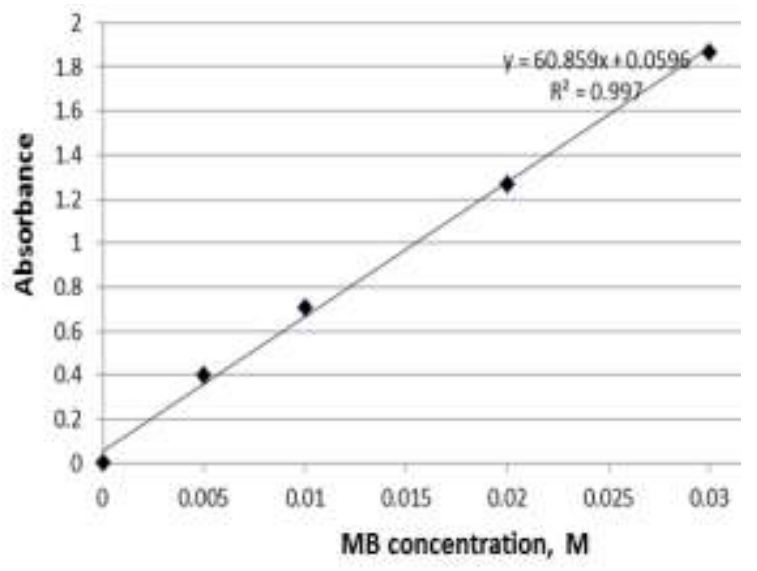

Figure 3: Methylene blue calibration spectrophotometric graph.

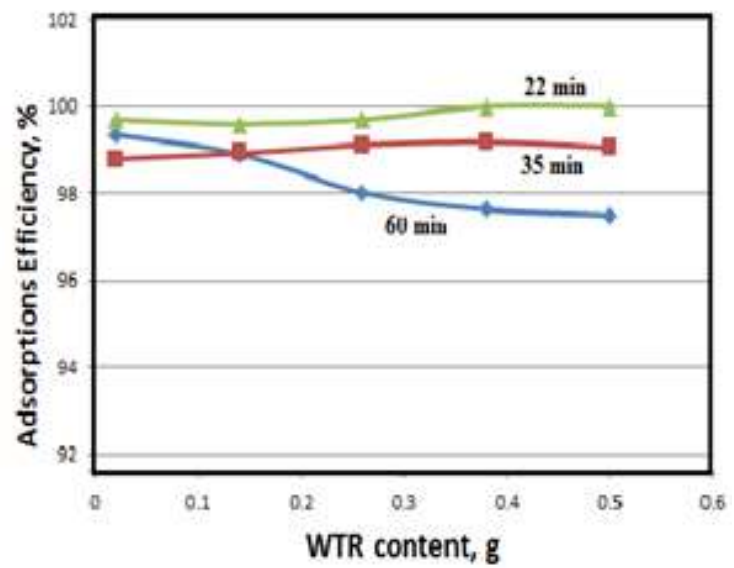

Figure 4: The adsorption profiles of methylene blue on the WTR.

The CEC of WTR evaluated by this method was found to be $10.5 \mathrm{mmol} / 100 \mathrm{~g}$. The CEC value was more than that of normal clay minerals [26] and much less than the modified clays [17].

For the surface area determination, a plot of the amount of $\mathrm{MB}$ added versus the amount of absorbed MB was constructed. The point of complete cation replacement was identified. The specific surface can then be calculated from the amount of MB absorbed at the optimum point:

$$
S_{\mathrm{s}}=\frac{m_{\mathrm{MB}}}{319.87} A_{\mathrm{v}} A_{\mathrm{MB}} \frac{1}{m_{\mathrm{s}}}
$$

where $\mathrm{m}_{\mathrm{MB}}$ was the mass of the absorbed $\mathrm{MB}$ at the point of complete cation replacement, and $\mathrm{m}_{\mathrm{s}}$ is the mass of the soil specimen, $A_{v}$ was Avogadro's number $\left(6.02 \times 10^{23} / \mathrm{mol}\right)$, and $\mathrm{A}_{\mathrm{MB}}$ was the area covered by one MB molecule (typically assumed to be $130 \AA^{2}$ ).

The surface area of the material was estimated using the above relation (Eq. 3) and found to be $87.5 \mathrm{~m}^{2} \cdot \mathrm{g}^{-1}$.

\section{Application for $\mathrm{PO}_{4}$ level control}

The phosphomolybdic acid method was employed for the determination of phosphate in water [18]. The standard solution was prepared in the range of 1-10 mh. $\mathrm{L}^{-1}$ and used to prepare the calibration graph. The absorption was measured at $660 \mathrm{~nm}$. The method was linear over the concentration range $0-10 \mathrm{mg} . \mathrm{L}^{-1}$ (Figure 5). The correlation coefficient was 0.982 and the absorbance was related to the concentration by equation 4.

$\mathrm{Abs}_{660 \mathrm{~nm}}=0.0629 \mathrm{C}\left(\mathrm{mg} \cdot \mathrm{L}^{-1}\right)+0.136$ 


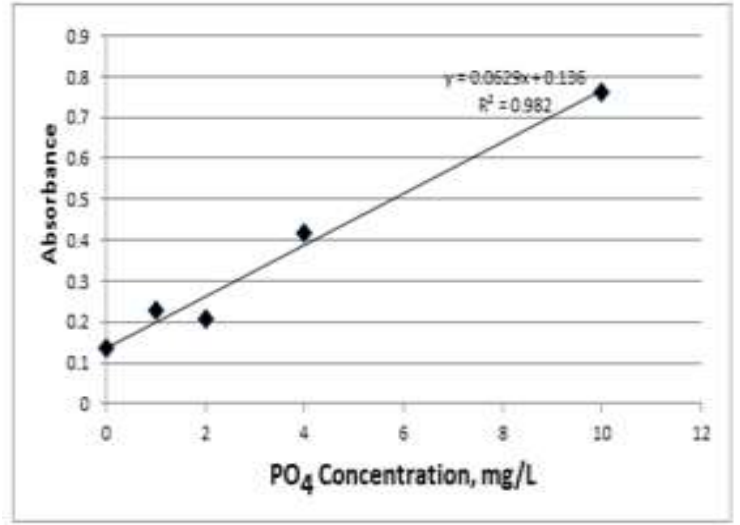

Figure 5: Phosphate spectrophotometric calibration graph.

In contact with WTR, the phosphate content underwent a significant decrease with time. Within $4 \mathrm{~h}$, there was $75 \%$ of the phosphate was removed from the water. Thus, about Ca-based WTR for soil amendment will participate in the control of phosphate level in the irrigation water by raising the soil $\mathrm{pH}$ and soil available $\mathrm{Ca}$ [9]. This allows safe disposal of water to the environment that no further implications may be expected. Quantitatively, $50 \mathrm{ml}$ of $50 \mathrm{mg} . \mathrm{L}^{-1}$ (i.e. $2.5 \mathrm{mg}$ of phosphate) will degrade down to 0.625 $\mathrm{mg}$ within $4 \mathrm{~h}$. Capacity wise will assume $1.6 \mathrm{mg}$ $\mathrm{PO}_{4}{ }^{3-} / \mathrm{g}$ of WTR. The time duration selection was based on the time required for the water to flood the soil and move downward. Gersten, [27] reported that the most significant factors affecting $\mathrm{P}$ removal rate with WTR were the particle size. He reported a total $\mathrm{P}$; TP, removal efficiency varied between $58-95 \%$. The increase in particle size from $\sim 0.6-2$ to $6-20 \mathrm{~mm}$ reduced the phosphate adsorption capacity by $30 \%$ on average within $6 \mathrm{~h}$.

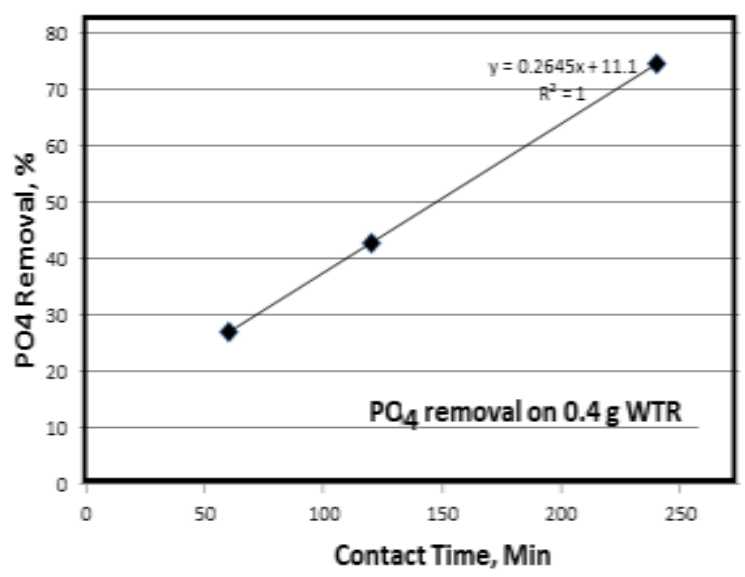

Figure 6: Phosphate removal curves.

The WTR also proved potential denitrification of water [15]. Makris et al. [16] studied the ability of WTR to immobilize excess soil phosphorus (P).
Kinetically, the WTRs exhibited a slow phase after a rapid initial phase. Maximum sorption capacity of Phosphorus sorption maxima 9100 $\mathrm{mg}$ of $\mathrm{P} \mathrm{kg}^{-1}$ was reported Methylene blue, MB, the dye is known in the application for the determination of soil properties including the cation exchange capacity, CEC, and specific surface area [17]. The methylene blue procedures yield an exact evaluation of some soil index properties. Further, they only need simple test equipment and are easy to apply.

\section{Conclusion}

The calcium-based water treatment residue proved a remarkable sorption activity towards dyes as a result of the relatively high surface area. The cation exchange capacity was comparable indicated a potential sorbent. The phosphate load of water can well be reduced using WTR and hence, a cheap soil amendment material to control the phosphate level may be recommended.

\section{Acknowledgment}

The authors are grateful to Mr. H. Mohammed for the XRD measurement.

\section{References}

[1] S. De Gisi, G. Lofrano, M. Grassi M. Notarnicola, Characteristics and adsorption capacities of low-cost sorbents for wastewater treatment: A review, Sustainable Mater. Technol., 9, , 10-40, 2016.

[2] Y. Yukselen, A. Kaya, Suitability of the methylene blue test for surface area, cation exchange capacity and swell potential determination of clayey soils, Eng. Geol. 102 38-45, 2008.

[3] L.Y. Lee, B. Wang, H. Guo, J.Y. Hu and S.L. Ong, Aluminum-based water treatment residue reuse for phosphorus removal, Water 7, 1480-1496, 2015.

[4] Y.-F. Zhou \& R. J. Haynes, Water treatment sludge can be used as an adsorbent for heavy metals in wastewater streams, Waste Manage. Environ. 140, 379-389, 2010.

[5] P. Punamiya, M. Pigna, A. Violante, D. Sarkar, Effect of particle size of drinking-water treatment residuals on the sorption of arsenic in the presence of competing ions, $\mathrm{J}$ Hazard. Mater., 260:644-51, 2013

[6] A. Suda, K. Baba, I. Akahane T. Makino, Use of water - treatment residue containing polysilicate-iron to stabilize arsenic in flooded soils and attenuate arsenic uptake by rice (Oryza sativaL.) plants, Soil Sci. Plant Nutr., 62 (2) 111-116, ) 2016.

[7] Y. Zhao, C. Wang, L.A. Wendling, and Y. Pei, Feasibility of Using Drinking WTR as a Novel Chlorpyrifos Adsorbent, J. Agric. Food Chem., , 61 (31), 7446-7452, 2013. 
[8] Park, S.-G. , Yahata, H.; Saeki, K.; Kurosawa, K. Kim, Y.-J., Physical Properties of Water Treatment Residue and Their Effects on Plant Growth as a Substitute Soil. J. Fac. Agricul., Kyushu Univ. 54, 481-487, 2009.

[9] J. Fan, Z. He, L. Q. Ma, Y. Yang and P. J. Stoffella, Impacts of calcium water treatment residue on the soilwater-plant system in citrus production, Plant Soil, 374:993-1004, 2014

[10] J. E. Hyde and T. F. Morris, Phosphorus Availability in Soils Amended with Dewatered Water Treatment Residual and Metal Concentrations with Time in Residual, J. Environ. Qual. 29:1896-1904, 2000.

[11] O. Ruzhitskaya, E. Gogina, 2017, Methods for Removing of Phosphates from Wastewater, MATEC Web Conf. 106, 07006, 2017.

[12] L. Chang-jun, L. Yan-zhong, L. Zhao-kun, C. Zhaoyang, Z. Zhong-guo, and J. Zhi-ping, Adsorption removal of phosphate from aqueous solution by active red mud, J. Environ. Sci. 19,1166-1170, 2007.

[13] M.M. Barbooti, Simple Method For Control of Phosphate Level of Manure Using Magnesium Oxide, Eng. Technol. J., 33 (4), 676-689, 2015.

[14] J. Goscianska, M. Ptaszkowska-Koniarz, M. Frankowski, M. Franus, R. Panek, Wojciech Franus, Removal of phosphate from water by lanthanum-modified zeolites obtained from fly ash, J. Colloid Interface Sci., 513, 72-81, 2018

[15] C. Wang, Y. Wu, L. Bai, Y. Zhao, Z. Yan, H. Jiang, $\mathrm{X}$. Liu, Recycling of drinking water treatment residue as an additional medium in columns for effective $\mathrm{P}$ removal from eutrophic surface water, J. Environ. Manag., 217, 363-372, 2018.

[16] B. Shyla Mahadevaiah G. Nagendrappa, "A simple spectrophotometric method for the determination of phosphate in soil, detergents, water, bone and food samples through the formation of phosphomolybdate complex followed by its reduction with thiourea, Spectrochim. Acta Part A: Molecular and Biomolecular Spectroscopy, 78(1), 497-502, 2011.

[17] J. A. A. Calábria, D. N. do Amaral, A. C. Q. Ladeira, S. D. S. Cota, and T. S. S. Silva, 2013, Determination of the cation exchange capacity of bentonite exposed to hyper alkaline fluid, Internat. Nucl. Atlantic Conf. - INAC Recife, PE, Brazil, November 24-29, 2013.

[18] American Society for Testing and Materials. ASTM C 837-81. Standard Test Methods of Methylene Blue Index of Clay. (1988).

[19] J.C. Santamarina, K.A. Klein, Y.-H. Wang, E. Prencke, Specific surface: Determination and relevance, Canad. Geotech. J., 39 (): 233-241, 2002.

[20] G. Chen, J. Pan, B. Han, H. Yan, "Adsorption of methylene blue on montmorillonite," J. Dispersion Sci. Technol., Vol. 20, No. 4, pp. 1179-1187, 1999.

[21] M. M. Barbooti, G. Bolzoni, I. A. Mirza, M. Pelosi, L. Barilli, R. Kadhum and G.Peterlongo, Evaluation of quality of drinking water from Baghdad, Sci. World J., 5(2), 35-46, 2010.
[22] National Institute of Standards and Technology, NIST, $\mathrm{CaCO}_{3}$ IR spectrum, 4659, 2009, Coblentz Society, Inc.

[23] A.S. Kamba, M., Ismail, T.A.T. Ibrahim, Z.A. Bakar Zakaria, Synthesis and Characterization of Calcium Carbonate Aragonite Nanocrystals from Cockle Shell Powder (Anadara granosa), J. Nanomaterials, Article ID 398357, 9 pages, 2013.

[24] K. C. Makris, W. G. Harris, G. A. O'Conno, and T. A. Obreza, Phosphorus Immobilization in Micropores of Drinking-Water Treatment Residuals: Implications for Long-Term Stability, Environ. Sci. Technol., 38 (24), pp 6590-6596, 2004.

[25] M. Galvan-Ruiz, J. Hernandez, L. Banos, J. NoriegaMontes and M.E. Rodriguez-Garcia, Characterization of calcium carbonate calcium oxide and calcium hydroxide as starting point to the improvement of lime for their use in construction. J. Mater. Civil Eng., 21(11):625-708, 2009.

[26] P.T. Hang, and G.W. Brindley, , "Methylene Blue Absorption by Clay Minerals. Determination of Surface Areas and Cation Exchange Capacities (Clay-Organic Studies XVIII), " Clays Clay Miner., Vol. 18, pp.203-212, 1970.

[27] B. Gersten, , A feasibility study in the use of domestic water treatment residuals to remove phosphorus from wastewater, Ph. D. Thesis, Cardiff University, UK, 2017. 